\title{
Nilai Manfaat Perikanan Bagi Nelayan Skala Kecil Di Kampung Parambu, Kabupaten Jeneponto
}

\author{
Muhammad Arhan Rajab \\ Fakultas Pertanian/Program Studi Agribisnis, Universitas Cokroaminoto Palopo \\ email:arhanrajab@gmail.com
}

\begin{abstract}
Abstrak
Penelitian ini bertujuan menghitung nilai manfaat langsung perikanan skala kecil di kawasan ekosistem mangrove di Kampung Parambu, Kab. Jeneponto. Pendekatan yang digunakan adalah penelitian sensus. Hasil yang didapat bahwa pemanfaatan sumberdaya ikan, kepiting, udang dan kerang sebesar Rp.319.252.000 per tahun. Pemanfaatan sumberdaya ikan sebesar Rp.124.516.000 per tahun, pemanfaatan sumberdaya kepiting sebesar Rp.90.242.000 per tahun, pemanfaatan sumberdaya udang sebesar Rp. 87.836.000 per tahun, pemanfaatan sumberdaya kerang sebesar Rp.16.658.000 per tahun. Nilai tersebut memberikan gambaran bahwa keberadaan sumberdaya ikan pada ekosistem mangrove di Kampung Parambu memberikan kontribusi ekonomi yang cukup besar bagi masyarakat setempat terutama bagi nelayan skala kecil. Oleh karena itu kebijakan dalam pengelolaan sumberdaya perikanan, perlu mempertimbangkan dampak sosial ekonomi yang akan terjadi terhadap masyarakat.
\end{abstract}

Kata Kunci: potensi, manfaat langsung, perikanan, skala kecil

\section{Pendahuluan}

Negara Indonesia dikenal sebagai negara bahari dimana wilayah lautnya mencakup tiga perempat luas Indonesia atau 5,8 juta $\mathrm{km}^{2}$ dengan garis pantai sepanjang $95.181 \mathrm{~km}$, sedangkan luas daratannya hanya 1,9 juta $\mathrm{km}^{2}$. Wilayah laut yang sangat luas tersebut mengandung sumber daya alam hayati dan jasa lingkungan yang sangat melimpah dan belum dikembangkan secara optimal. Perairan laut Indonesia memiliki jenis ikan yang melimpah sekitar 3.000 jenis ikan (Dahuri, 2001).

Pengelolaan sumberdaya wilayah pesisir dan lautan di Indonesia dari sudut pandang pembangunan berkelanjutan (sustainable development) dihadapkan pada kondisi yang mendua, yaitu di satu pihak, ada beberapa kawasan pesisir yang telah dimanfaatkan dengan intensif. Tetapi dipihak lain, pemanfaatan tersebut mengakibatkan terlampauinya daya dukung dari ekosistem, seperti pencemaran, tangkapan berlebih (over fishing), degradasi fisik habitat pesisir, dan abrasi pantai (Rusila Noor, dkk, 1999).

Salah satu sumber daya alam yang dapat diperbaharui adalah ekosistem mangrove dengan berbagai biota yang memiliki nilai ekonomis yang tinggi. Hutan mangrove adalah vegetasi hutan yang tumbuh dan berkembang dengan baik disepanjang pantai, muara sungai yang dipengaruhi oleh pasang surut air laut. Hutan ini berada di titik pertemuan antara laut dan darat dengan ekosistem yang mempunyai bermacam-macam fungsi. Dari kurang lebih 15,9 juta ha hutan mangrove didunia, sekitar $27 \%$ atau 4,25 juta ha diantaranya terdapat di Indonesia (Bengen, 2000).

Hutan mangrove memiliki fungsi ekologis dan ekonomis yang sangat bermanfaat bagi manusia. Secara ekologis, hutan mangrove berfungsi sebagai daerah pemijahan (spawning grounds), daerah pembesaran (nursery grounds) dan tempat mencari makan bagi beraneka jenis biota laut. Selain itu, serasah mangrove yang jatuh di perairan menjadi sumber pakan biota perairan dan unsur hara yang sangat menentukan produktivitas perikanan perairan laut di depannya. Lebih jauh, hutan mangrove juga merupakan habitat bagi berbagai jenis burung, reptilia, mamalia dan jenis-jenis kehidupan lainnya, sehingga hutan mangrove menyediakan keanekaragaman hayati (biodiversity) dan plasma nutfah (genetic pool) yang tinggi serta berfungsi sebagai sistem penyangga kehidupan. Dengan sistem perakaran yang rapat dan kokoh, hutan mangrove juga berfungsi sebagai pelindung daratan dari gempuran gelombang dan angin topan, penahan abrasi, intrusi air laut dan gaya-gaya kelautan yang ganas lainnya. Secara ekonomi, hutan mangrove dapat dimanfaatkan kayunya secara lestari untuk bahan bangunan, arang dan bahan baku kertas. Selain itu hutan mangrove juga berfungsi sebagai kawasan wisata alam pantai, sebagai obyek pendidikan, penelitian dan pengembangan ilmu pengetahuan (Bengen, 2000).

Sejalan dengan perubahan waktu, pemanfaatan hutan mangrove semakin berkembang pada berbagai sektor pembangunan dalam usaha memenuhi kebutuhan hidup manusia. Konversi hutan mangrove untuk berbagai macam kegiatan seperti perikanan, pertanian, industri, pariwisata dan lainnya terjadi hampir di seluruh wilayah Indonesia, hal ini menyebabkan terjadinya penyusutan luas hutan mangrove. Saat ini hutan mangrove di Indonesia diperkirakan tinggal sekitar 2,3 juta ha. Konversi hutan mangrove untuk berbagai kegiatan merupakan ancaman bagi kelestarian hutan mangrove dan tentunya akan menimbulkan dampak bagi kehidupan sosial ekonomi masyarakat disekitar kawasan tersebut. Mengingat pentingnya manfaat hutan mangrove yang telah dikemukakan di atas, maka setiap konversi hutan mangrove untuk berbagai macam kegiatan hendaknya terlebih dahulu menghitung manfaat dan kerugiannya 
secara keseluruhan bagi masyarakat. Untuk itu diperlukan suatu perencanaan dan pengelolaan dalam memanfaatkan sumberdaya hutan mangrove secara berkelanjutan. Salah satu faktor yang perlu dipertimbangkan dalam pengambilan keputusan pengelolaan sumber daya hutan adalah nilai (valuasi) ekonomi dari sumberdaya hutan yang bersangkutan. Tersedianya informasi tentang nilai ekonomi sumberdaya tersebut akan membantu pengelola hutan untuk bertindak ekonomis dalam menetapkan kebijakan pemanfaatan hutan (Dixon, 1993).

Salah satu ekosistem sumber daya mangrove di Kabupaten Jeneponto adalah Kampung Parambu, Kel. Togo-Togo, Kecamatan Batang. Terlepas dengan adanya abrasi pantai, ekosistem mangrove di Kampung Parambu ternyata mampu memberikan manfaat secara langsung bagi masyarakat Kampung Parambu. Dengan status kepemilikan yang belum jelas dan adanya nilai manfaat penting dari sumber daya yang sifatnya tidak nampak dan sulit diukur secara moneter menyebabkan persepsi masyarakat di Kampung Parambu cenderung kurang mengetahui bahkan sama sekali tidak memiliki kepedulian terhadap pengelolaan dan pelestarian sumber daya tersebut rendah pula.

Pentingnya pertimbangan fungsi ekologi dan ekonomi ekosistem mangrove tersebut maka tujuan dari penelitian ini adalah mengkaji karakter dan penilaian langsung nilai ekonomi dari pemanfaatan perikanan dan pemanfaatan lahan disekitar ekosistem mangrove untuk memberikan gambaran secara jelas mengenai pembangunan dan pengelolaan sumber daya perikanan dan kelautan terkait dengan judul penelitian ini yaitu "Nilai Manfaat Perikanan Bagi Nelayan Skala Kecil di Kampung Parambu, Kab. Jeneponto".

\section{Bahan dan Metode}

\section{Waktu dan Tempat}

Penelitian ini dilakukan di Kampung Parambu, Kel. Togo-Togo, Kec. Batang, Kab. Jeneponto, pada bulan Agustus sampai September 2019. Lokasi ini dipilih dengan pertimbangan bahwa daerah tersebut merupakan salah satu kampung nelayan dimana terdapat kawasan ekosistem mangrove yang besar sebagai tempat mencari ikan dan berdasarkan data Dinas Kelautan dan Perikanan Kab. Jeneponto.

\section{Jenis Penelitian}

Jenis penelitian yang digunakan adalah dengan menggunakan metode sensus yaitu penelitian yang mengambil semua individu yang ada dalam populasi sebagai responden dengan menggunakan kuesioner sebagai alat pengumpul data yang pokok, dimana responden yang dijadikan sampel adalah golongan pemanfaat mangrove.

\section{Teknik Pengambilan Sampel}

Metode pengambilan sampel/responden dengan menggunakan metode sensus yaitu metode pengambilan sampel dengan mengambil semua individu yang ada dalam populasi sebagai sampel responden. Metode ini dipergunakan untuk menilai manfaat langsung.

Adapun jumlah responden yang menjadi sampel sebanyak 30 orang. Populasi dan sampel penelitian ini adalah nelayan kecil yang mencari ikan pada kawasan ekosistem mangrove di kampung Parambu.

\section{Teknik Pengumpulan Data}

Teknik pengumpulan data yang digunakan dalam penelitian ini yaitu:

1. Observasi, yaitu pengamatan langsung terhadap berbagai kegiatan dan keadaan di lokasi penelitian yang terkait dengan tujuan penelitian.

2. Wawancara, yaitu mengumpulkan data dengan melakukan wawancara dengan menggunakan kuisioner kepada pihak terkait yang berkaitan dengan penelitian.

\section{Sumber Data}

Data yang dikumpulkan pada penelitian ini meliputi data primer dan data sekunder, dengan jenis data sebagai berikut :

1. Data primer, yaitu data yang diperoleh langsung dari lapangan melalui wawancara dengan responden menggunakan kuisioner dan pengamatan (observasi) langsung di lapangan.

2. Data sekunder, yaitu data yang diperoleh dari instansi-instansi terkait dengan masalah dan obyek yang diteliti.

\section{Analisis Data}

Data dianalisis secara deskriptif dan kuantitatif. Analisis data secara deskriptif digunakan untuk menjelaskan aktivitas masyarakat yang memanfaatkan ekosistem mangrove di Kampung Parambu. Analisis data secara kuantitatif digunakan untuk menghitung nilai manfaat langsung ekosistem mangrove di Kampung Parambu. Menurut Tuwo (2011) untuk menghitung nilai manfaat langsung ekosistem mangrove dapat digunakan metode analisis sebagai berikut:

\section{Nilai Ikan}

Nilai ikan dihitung berdasarkan jumlah hasil tangkapan per tahun dikalikan dengan harga jual. Dapat dihitung dengan menggunakan rumus :

$$
\text { Nilai Ikan }=(\mathrm{T} \times \mathrm{H})-\mathrm{B}(\mathrm{Rp} / \mathrm{th})
$$

Dimana,

$$
\begin{array}{lll}
\mathrm{T} & =\text { Tangkapan ikan }(\mathrm{kg} / \mathrm{th}) \\
\mathrm{H} & =\text { Harga jual } \quad(\mathrm{Rp} / \mathrm{kg}) \\
\mathrm{B} & =\text { Biaya operasional }(\mathrm{Rp})
\end{array}
$$

2. Nilai Udang 
Nilai udang dihitung berdasarkan jumlah hasil tangkapan per tahun dikalikan dengan harga jual. Dapat dihitung dengan menggunakan rumus :

Nilai Udang $=(\mathrm{T} \times \mathrm{H})-\mathrm{B}(\mathrm{Rp} / \mathrm{th})$

Dimana,

$$
\begin{array}{lll}
\mathrm{T} & =\text { Tangkapan udang }(\mathrm{kg} / \mathrm{th}) \\
\mathrm{H} & =\text { Harga jual } \quad(\mathrm{Rp} / \mathrm{kg}) \\
\mathrm{B} & =\text { Biaya operasional }(\mathrm{Rp})
\end{array}
$$

\section{Nilai Kepiting}

Nilai kepiting dihitung berdasarkan jumlah hasil tangkapan per tahun dikalikan dengan harga jual. Dapat dihitung dengan menggunakan rumus :

$$
\text { Nilai Kepiting }=(\mathrm{T} \times \mathrm{H})-\mathrm{B}(\mathrm{Rp} / \mathrm{th})
$$

Dimana,

$$
\begin{array}{ll}
\mathrm{T} & =\text { Tangkapan kepiting (ekor/th) } \\
\mathrm{H} & =\text { Harga jual } \quad(\mathrm{Rp} / \mathrm{ekor}) \\
\mathrm{B} & =\text { Biaya operasional }(\mathrm{Rp})
\end{array}
$$

\section{Nilai Kerang}

Nilai kerang dihitung berdasarkan jumlah hasil tangkapan per tahun dikalikan dengan harga jual. Dapat dihitung dengan menggunakan rumus :

Nilai Kerang $=(\mathrm{T} \times \mathrm{H})-\mathrm{B}(\mathrm{Rp} / \mathrm{th})$

Dimana,

$$
\begin{array}{ll}
\mathrm{T} & =\text { Tangkapan kerang (ekor/th) } \\
\mathrm{H} & =\text { Harga jual } \quad(\mathrm{Rp} / \mathrm{ekor}) \\
\mathrm{B} & =\text { Biaya operasional }(\mathrm{Rp})
\end{array}
$$

Untuk menghitung nilai total manfaat langsung ekosistem mangrove, dapat dilihat pada rumus sebagai berikut :

$$
\begin{aligned}
& \text { Nilai Manfaat Langsung }(\mathrm{NML})= \\
& \qquad \sum_{I=0}^{n} M L 1+M L 2+\ldots . .+n
\end{aligned}
$$

Dimana,

$$
\begin{aligned}
& \text { ML }=\text { Manfaat langsung } \\
& \text { ML1 }=\text { Nilai manfaat langsung ikan } \\
& \text { ML2 }=\text { Nilai manfaat langsung udang } \\
& \text { ML3 }=\text { Nilai manfaat langsung kepiting } \\
& \text { ML4 = Nilai manfaat langsung kerang }
\end{aligned}
$$

\section{Hasil}

\section{Kondisi Ekosistem Mangrove}

Kawasan sumberdaya ekosistem mangrove di Kabupaten Jeneponto secara administratif pemerintahan mencakup tujuh wilayah kecamatan, yaitu Kecamatan Arungkeke, Kecamatan Batang, Kecamatan Tarowang, Kecamatan Tamalatea, Kecamatan Binamu, Kecamatan Bangkala, Kecamatan Bangkala barat.

Penyebaran kawasan sumberdaya ekosistem mangrove di Kabupaten Jeneponto secara keseluruhan yakni 282,50 Ha (Kondisi baik 119,50 Ha, Rusak ringan 1,50 Ha dan Rusak berat 161,50 Ha). Akan tetapi dengan penyebaran kawasan sumberdaya mangrove pada tujuh Kecamatan di Kabupaten Jeneponto ternyata tidak didukung dengan adanya kesadaran masyarakat pada umumnya untuk menjaga kawasan tersebut agar tetap lestari. Dampak yang kemudian ditimbulkan bahwa hampir sebagian besar kawasan sumberdaya ekosistem mangrove dalam kondisi rusak berat. Menanggapi situasi tersebut Pemerintah Kabupaten Jeneponto dalam hal ini Dinas Kelautan dan Perikanan tidak tinggal diam dengan langsung melakukan rehabilitasi pada titik-titik yang dianggap dalam kondisi rusak berat serta melakukan penyuluhan manfaat penting terhadap kawasan ekosistem mangrove (BPS, Kab. Jeneponto. 2018).

\section{Nilai Manfaat Langsung Perikanan Skala Kecil pada Ekosistem Mangrove di Kampung Parambu}

\section{Nilai Ekonomi Ikan}

Penangkapan ikan dilakukan secara berpindahpindah, frekuensi penangkapan 10-25 kali/bulan. Jumlah tangkapan persatu kali penangkapan 2-5, dengan harga ikan di pasar lokal sebesar Rp. 20.000/Kg.

\section{Nilai Ekonomi Kepiting}

Berdasarkan hasil penelitian menunjukkan bahwa frekuensi penangkapan kepiting dalam sebulan relatif bervariasi, yaitu antara 12 - $16 \mathrm{kali} / \mathrm{bulan}$ atau pertahun antara 144 - $192 \mathrm{kali} /$ tahun atau rata-rata $168 \mathrm{kali} /$ tahun. Jumlah tangkapan per satu kali penangkapan antara $1-5$ $\mathrm{kg}$ dengan harga jual per $\mathrm{kg}$ berkisar antara $\mathrm{Rp}$. $25.000 / \mathrm{Kg}$.

\section{Nilai Ekonomi Udang}

Berdasarkan hasil penelitian menunjukkan bahwa frekuensi penangkapan kepiting dalam sebulan relatif bervariasi, yaitu antara 10 - $16 \mathrm{kali} / \mathrm{bulan}$ atau pertahun antara 120 - $192 \mathrm{kali} /$ tahun atau rata-rata $156 \mathrm{kali} / \mathrm{tahun}$. Jumlah tangkapan per satu kali penangkapan antara $3-5$ $\mathrm{kg}$ dengan harga jual per $\mathrm{kg}$ berkisar antara $\mathrm{Rp}$. $25.000 / \mathrm{Kg}$.

\section{Nilai Ekonomi Kerang}

Berdasarkan hasil penelitian menunjukkan bahwa frekuensi penangkapan kepiting dalam sebulan relatif bervariasi, yaitu antara 5 - $10 \mathrm{kali} / \mathrm{bulan}$ atau pertahun antara 60 - $120 \mathrm{kali} / \mathrm{tahun}$ atau rata-rata $96 \mathrm{kali} / \mathrm{tahun}$. Jumlah tangkapan per satu kali penangkapan antara 5-10 $\mathrm{kg}$ dengan harga jual per kg Rp. 13..500/Liter.

Berdasarkan data tersebut diatas diperoleh total penerimaan pemanfaatan langsung ikan sebesar Rp. 47.709.000,-. Sedangkan total biaya pemanfaatan langsung ikan sebesar Rp. 31.051.000,-. Jadi dapat diketahui nilai pendapatan bersih ikan sebesar Rp 47.709.000 - Rp. 31.051.000=Rp. 16.658.000/Tahun.

\section{Kesimpulan}

Berdasarkan hasil penelitian identifikasi jenis dan nilai manfaat langsung ekosistem mangrove di Kampung Parambu, Kecamatan Batang, Kabupaten Jeneponto, maka dapat ditarik kesimpulan bahwa pemanfaatan sumberdaya perikanan skala kecil yaitu ikan, kepiting, udang dan 
kerang sebesar Rp. 319.252.000 per tahun. Pemanfaatan sumberdaya ikan sebesar Rp. 124.516.000 per tahun, pemanfaatan sumberdaya kepiting sebesar Rp. 90.242.000 per tahun, pemanfaatan sumberdaya udang sebesar Rp. 87.836.000 per tahun, pemanfaatan sumberdaya kerang sebesar Rp. 16.658.000 per tahun.

\section{Ucapan Terima Kasih}

Ucapan terima kasih kami ucapkan kepada seluruh masyarakat nelayan kecil Kampung Parambu yang menerima kami dengan baik untuk melakukan penelitian ini. Tak lupa juga kami haturkan ucapan terima kasih kepada Dinas Kelautan dan Perikanan Kabupaten Jeneponto dan Camat Batang atas bantuan untuk memberikan izin melakukan penelitian dan menyediakan data-data pendukung penelitian.

\section{Daftar Pustaka}

Bengen, D.G. 2000. Pedoman Teknis Pengenalan dan Pengelolaan Ekosistem Mangrove. Pusat Kajian Sumber Daya Pesisir dan Lautan. IPB. Bogor.

BPS, Kab. Jeneponto. 2018. Kecamatan Batang Dalam Angka 2010. Badan Pusat Statistik Kab. Jeneponto. Jeneponto

Dahuri, 2001. Pengelolaan Sumberdaya Wilayah Pesisir dan Lautan Secara Terpadu. PT. Pradnya Paramitha. Jakarta

Dixon, J.A. dan Hufschmidt, M.M.,1993. Teknik Penilaian Ekonomi Terhadap Lingkungan (Suatu Buku Kerja Studi Kasus). Gadjah Mada University Press, Yogyakarta.

Rusila Noor, Y., M. Khazali, dan I N.N. Suryadiputra. 1999. Panduan Pengenalan Mangrove di Indonesia. PHKA/WI-IP, Bogor.

Tuwo,. Ambo. 2011. Pengelolaan Ekowisata Pesisir dan Laut (Pendekatan Ekologi, Sosial Ekonomi, Kelembagaan dan Sarana Wilayah). Brilian Internasional. Surabaya. 